\title{
Strengthening general practice in deprived localities
}

The White Paper Equity and Excellence: Liberating the $N H S^{1}$ has placed clinicians firmly in the driving seat to determine the nature and quality of care for our patients. The role proposed for general practice has been enhanced so that we will take increasing responsibility for commissioning appropriate services, and work with local authorities to improve the quality of health through more personalised care with emphasis on prevention.

Future commissioning of secondary care could take place through general practice consortia working together and working with their local provider trusts. However, these changes are proposed at a time of unprecedented financial constraints, both within the NHS and globally. These financial pressures and the imperative to deliver care as close to the patient as possible will lead to more care moving into the community. One of the current pressure points is the increased attendance at emergency departments; another is managing patients with longterm conditions and comorbidities. ${ }^{1}$

\section{RECOMMENDATIONS FOR TRAINING}

The review of the Working Time Directive's impact on training healthcare professionals, Time for Training, ${ }^{2}$ has made some important recommendations for the future delivery of care, so that doctors and other healthcare professionals in training are able to develop the skills and behaviours necessary to deliver future health care. It recommends more consultant presence throughout the 24hour period, particularly for the acute specialties, and greater use of the multiprofessional team.

The changes in service delivery necessary to implement both of these reports will be difficult to implement without strong general practice, particularly in areas with the greatest health needs.

More than a decade ago, a study in the North West of England anticipated that without change there would be an insufficient number of GPs to provide care in parts of the country. The two Directors of Postgraduate General Practice Education in the North West, Doctors Mathie and McKinlay, produced a guide which outlined ways in which primary care trusts (PCTs) could expand their training practices and establish, retain, and recruit their future workforce. $^{3}$ The authors had not anticipated the financial pressure to deliver more patient care in the community, nor did they predict the enhanced role that would be expected of future general practice in leading the shape of healthcare services. These additional pressures will make it all the more important that we plan the future workforce and ensure it is fit for purpose.

Russell and Lough ${ }^{4}$ have described the current situation in Scotland where, although there has been a significant increase in doctors' training for general practice over the past decade, there has been little increase in training practices in areas providing care for the most deprived populations.

In England, the Centre for Workforce Intelligence has produced its first report on the medical workforce. ${ }^{5}$ This report outlines the current under-supply of GPs across England but, more importantly, it highlights a significant difference between the strategic health authorities: those in the north of the country are below capitation for trained doctors and those in training. The Centre for Workforce Intelligence report also emphasises that the numbers recruited to training programmes in 2009 was lower than the places available; in 2010 all the training programmes were filled, but only on the second round.

The situation within each strategic health authority is a microcosm of the national picture. The training programmes in the popular suburbs have been able to recruit, while the more deprived rural and inner city areas have had difficulty. Selection into medical training programmes allows trainees who rank the highest to choose their preferred scheme, thus the most able trainees choose to work in the more popular areas and become trainers.

\section{TRAINING SUPPORT}

Attempts are being made to redress the balance. In 2009 the Royal College of General Practitioners established First5, which aims to support doctors from completion of training through their first 5 years in practice. Selection into training has been developed, and there is good correlation with the three-stage process, particularly the situational judgment test and success in the MRCGP exam. ${ }^{6}$ Finally, there are proposals to extend the length of training to encourage development of additional skills necessary for our future roles. $^{7}$

More than a decade ago, a study in North West England and Oxford identified the difficulties facing new principals. ${ }^{8}$ These findings were used to establish a systematic approach to supporting doctors in their first 5 years after completing training. ${ }^{9}$ The strategies used in North West England included targeting the areas where training practices were sparse or absent, and securing sponsorship for participants from the PCT. The results were encouraging, and the programme was expanded to support more senior practitioners, many of whom were in more deprived areas. ${ }^{10}$

Course participants in the programme were encouraged to prepare themselves and their practices for training, including providing undergraduate and foundation placements. Many have progressed to leadership positions in training and in their PCT. The North Western Deanery worked with the SHA and used the practice improvement initiatives to identify funding for practice development targeted at areas where training practices were sparse and there was potential for training.

The programme for new principals was developed in the early part of the decade 
at the same time as the Deanery team worked together across primary and secondary care, and with trust directors of medical education, to expand the hospitalbased opportunities for general practice trainees, and to ensure that foundation programmes included a post in the community. Thus doctors were encouraged to apply for a programme which would enable them to stay in one location throughout their foundation training; many then chose to stay to complete their general practice training in the same locality.

The element of this approach was to raise the profile of general practice as a career, attracting medical students and foundation trainees, and minimising some of the negative messages that previously existed. ${ }^{11}$

\section{SUSTAINED IMPROVEMENT}

Future recruitment of GPs to deprived areas will need sustained action. It is important that selection panels for undergraduate medical training have a balance of practitioners from primary and secondary care to identify potential leaders and innovators for primary care as well as secondary care and academia. Fifty per cent of our graduates need to aspire to a career in general practice to meet healthcare targets, and if we are to reverse the current health inequalities, the most able of that group are needed in deprived areas.

As we head into new structures for the NHS in England, it is essential that there remains a robust process to develop initiatives established in the last decade that encourage and enable practices in more deprived areas to meet standards for training. We also need strong commissioning of both primary and secondary care that takes account of not only the service requirements for the current population, but also ensures sound roots for training, particularly for general practice training in more deprived areas.

\section{Jacky Hayden,}

Dean of Postgraduate Medical Studies, North Western Deanery, Manchester.

\section{Provenance}

Commissioned; not peer reviewed.

\section{REFERENCES}

1. Department of Health. Equity and excellence: liberating the NHS. London: Department of Health, 2010

2. Temple J. Time for training. A review of the impact of the European Working Time Directive on the quality of training. London: Medical Education England, 2010. http://www.mee.nhs.uk/PDF/14274\%20Bookmark\% 20Web\%20Version.pdf (accessed 1 Oct 2010).

3. Mathie T, McKinlay D. A general practitioner retirement survey in the North West Region. Leeds: NHS Executive, 1999.

4. Russell M, Lough M. Deprived areas: deprived of training? Br J Gen Pract 2010; 60(580): 846-848.

5. Centre for Workforce Intelligence. Recommendation for general practice training 2011. London: Centre for Workforce Intelligence, 2010.

http://www.cfwi.org.uk/intelligence/cfwi-medicalsummary-sheets/recommendation-for-generalpractice-training-2011 (accessed 1 Oct 2010).

6. Irish W, Patterson F. Selecting general practice specialty trainees: where next? Br J Gen Pract 2010; 60(580): 849-852.

7. Manek N, Allen K. Changes to GP training. London: BMJ Careers, 2009.

http://careers.bmi.com/careers/advice/viewarticle.html?id=20000259 (accessed 1 Oct 2010).

8. Baron R, Evans J, Hasler J, et al. The training needs of young principals. Education for General Practice 1998; 9: 404-409.

9. Baron R, McKinlay D, Martin J, et al. Higher professional education for GPs in the North West of England - feedback from the first three years. Education for Primary Care 2001; 12: 421-429.

10. Baron R, McKinlay D, Martin J, Ward B. Masters degree-accredited professional education and development courses for general practitioners in the North Westner Deanery1997-2002: impact on effectiveness, retention and recruitment to additional roles. Education for Primary Care 2006; 17: 147-154.

11. Woodcock I. Foundation Year 2: changing attitudes towards general practice. Br J Gen Pract 2006; 56(532): 895 .

DOI: 10.3399/bjgp10X538912

\section{ADDRESS FOR CORRESPONDENCE}

\section{Jacky Hayden}

North Western Deanery, Three Piccadilly

Place, Manchester, M1 3BN.

E-mail: j.hayden@nwpgmd.nhs.uk 